Research Article

\title{
Construction of WeChat Mobile Teaching Platform in the Reform of Physical Education Teaching Strategy Based on Deep Neural Network
}

\author{
Yufeng $B a \mathbb{D}^{1}$ and Lin Qi $\mathbb{i D}^{1,2,3}$ \\ ${ }^{1}$ Institute of Physical Education, Henan Agriculture University, Zhengzhou 450046, Henan, China \\ ${ }^{2}$ Railway Police College, Zhengzhou 450053, Henan, China \\ ${ }^{3}$ Zhengzhou Key Laboratory of Criminal Science and Technology, Zhengzhou 450053, Henan, China
}

Correspondence should be addressed to Yufeng Ba; yufengba@henau.edu.cn

Received 27 April 2021; Revised 16 May 2021; Accepted 20 May 2021; Published 7 June 2021

Academic Editor: Sang-Bing Tsai

Copyright ( 2021 Yufeng Ba and Lin Qi. This is an open access article distributed under the Creative Commons Attribution License, which permits unrestricted use, distribution, and reproduction in any medium, provided the original work is properly cited.

\begin{abstract}
Physical education is an important part of school education. Doing a good job of physical education can not only increase students' interest in sports but also improve their physical fitness. However, traditional physical education methods lack new ideas and fail to reach the goals of physical education. Therefore, it is extremely urgent to conduct physical education teaching strategies. Based on this, this paper proposes the construction of WeChat mobile teaching platform in the reform of physical education teaching strategy based on deep neural network. This paper adopts literature method and experimental analysis method to conduct in-depth research on the application of deep neural network in physical education and its characteristics, shortcomings, and improvements and build a WeChat mobile based on deep neural network in physical education strategy reform teaching platform. The comparison between the control group and the experimental group is used to compare multiple physical test indicators before and after the test to reflect the teaching effectiveness after the change in the physical education strategy of this paper. This paper mainly analyzes the results of the physical education teaching scale and the results of the students' physical fitness test, including the students' learning motivation, learning attitude, and learning process in the physical education process, as well as the male and female students' results of the experimental group and the control group before and after the test compared. The $P$ values of the boys in the experimental class and the control class are all greater than 0.05 , which is limited to the relatively short time of the experiment. The data of the boys in the two classes on these three items show no significant difference. The $t$-test was performed on the posttest results of the three items of the girls, the $P$ values were all less than 0.05 , and there were significant differences, especially in the comparison of the results of the postthrowing solid ball and the corner running. The $P$ values of the two test items were all less than 0.01 ; there is a very significant difference.
\end{abstract}

\section{Introduction}

With the rapid development of our country's economy, the country pays more and more attention to the physical fitness of the people, and the physical education in schools is playing an increasingly important role. Traditional teaching methods enable students to have a deeper understanding of the "three foundations," which also brings certain positive effects to the cultivation of students' will and quality. However, the current education system is repetitive and lacks innovation. There are no fun and flexibility in the education process, which curbs the student's personality development. The emphasis is on physical training, which is basically the task of completing the new curriculum model. This cannot meet the physical movement needs of most students, thus affecting the development of students.

In order to improve computer technology, in recent years, deep learning networks have become a hotspot and direction of research. Deep neural network is the field of computer simulation for studying human behavior and 
thinking process. Its purpose is to allow machines to understand human information, describe information reasonably, and process it. Text, sound, and pictures are important media for people to understand the environment. Computers can make corresponding intelligent decisions by processing text, voice, images, and other pieces of information, so as to liberate human beings at a higher level and improve their quality of life. Great progress has been made in the fields of image classification, industrial detection, language processing, medical data, machine translation, recognition, and so on.

Peterson psychology research for decades has been devoted to modeling how people learn characteristics and categories. The empirical verification of these theories is usually based on artificial stimuli with simple representations. Recently, in tasks such as recognizing objects in natural images, deep neural networks have reached or surpassed human accuracy. These networks learn representations of real-world stimuli and can potentially use them to capture mental representations. They found that the stateof-the-art object classification network provides surprisingly accurate predictions of human similarity to natural images, but it cannot capture certain structures represented by humans. They showed that a simple transformation to correct these differences can be obtained through convex optimization. They use result notation to predict the difficulty of learning novel categories of natural images. Their results expand the scope of psychological experiments and computational models by extending the ease of use of large natural stimulus sets. However, their experimental results did not clearly indicate the application of deep neural networks and their solutions [1]. The study of EscrivaBoulley is a cluster randomized controlled trial that examines the effectiveness of teacher professional development (TPD) programs based on self-determination theory to increase the need for supportive incentives for primary school teachers, thereby enhancing their students' physical activity during physical education (PE) classes. Participants were 15 elementary school teachers and 293 students. The teachers in the treatment state received sports-related notebooks in one school year and participated in four 3-hour workshops. Teachers in the control state only received notebooks [2]. The students' PE and teachers' motivation methods were evaluated four times through accelerometer and observation method. The results showed that, in most school years, teachers in treatment state increased their psychological impact on students. They need support, but the level of the fourth measurement dropped slightly. The students in the treatment state increased the time spent on moderate to vigorous exercise time (MVPA) regardless of the exercise taught. However, their research showed that the method has different effects on different students, and there is no clear description of the experimental results in different situations [3]. Nielsen is an important place to promote physical exercise. However, school-based programs often face implementation challenges. To ensure the effectiveness of future interventions, it is considered important to identify the factors that affect the implementation process. The purpose of this research is to determine the factors that affect the early stages of the implementation of the plan, which has tripled the number of physical education at the elementary level. The publicly provided procedure descriptions and meeting minutes were documented for analysis. The document analysis was supplemented by two semistructured group interviews with the main project manager to collect in-depth project experience and perspectives. The results show that early participation by the school can ensure the best match between the plan and the school's needs and resources, and the ongoing shared partnership can help plan managers solve the plan's challenges in the early stages. It seems to be the core element of the reservation. However, although the school's sports facilities are guaranteed, the teaching quality of teachers also needs to be improved accordingly $[4,5]$.

The innovations of this paper are as follows: (1) combining qualitative research with quantitative research and fully analyzing the research data; (2) combining theoretical research with empirical research and combining physical education teaching on the basis of deep neural network theory. And investigation of strategy implementation is empirical.

\section{Research Method of Physical Education Teaching Strategy Based on Deep Neural Network Physical Test Analysis}

\subsection{Training Method of Deep Neural Network}

2.1.1. Forward Propagation. We regard the convolutional layer, activation function layer, and pooling layer as the basic structure of the convolutional neural network. The convolutional neural network generally contains many serial connections of such basic structures. Here, we define the loss function in terms of mean square error $[6,7]$ :

$$
R=\frac{1}{2} \sum_{p=1}^{P}\left(y_{p}-b_{p}^{L}\right)^{2} .
$$

Among them, $P$ is the dimension of the output result. For classification problems, $P$ represents that there are $P$ types of final classification results, where $b_{p}^{L}$ represents the output vector of the $L$ th layer. When $l=L$, it represents the output vector of the last layer, which is our final output result [8]. Among them,

$$
b^{l}=g\left(i^{l}\right)
$$

where $g$ is our nonlinear activation function, which is used to constrain the result of convolution within a certain range and make the model nonlinear [9]. $i^{l}$ is the output after the convolutional layer, which is calculated as follows:

$$
i^{l}=E^{l} b^{l-1}+c^{l} \text {. }
$$

Our goal is to continuously update these parameters so that the final output of the network $b^{L}$ is closer to the true value $y_{p}$, that is, to minimize the loss function $R$ of the model $[10]$. 
Formulas (1) and (3) are the basic formulas of forward propagation. Each layer has input and output. The input of each layer is the output of the previous layer, and the output of each layer will also be used as the next layer input (except the last layer) $[6,11]$. In this way, the sample information is transferred layer by layer from the first input layer, and finally, a predicted value will be obtained [12]. There must be an error between the predicted value and the true value, and the error loss function is used to measure the size of this error [13]. Our ultimate goal is to find the parameter that minimizes this error function. Finding this optimal parameter is realized by backpropagation algorithm. Figure 1 is a simple convolutional neural network (this picture is borrowed from Baidu Gallery, as shown in Figure 1: https:// wenku.baidu.com/view).

2.1.2. Backpropagation. Through forward propagation, we can get the final predicted value $b_{p}^{L}$, and by defining the error between the predicted value $b_{p}^{L}$ and the true value $y_{p}$, we get $R[14,15]$. To solve the parameter that minimizes the error $R$, we need to use our backpropagation algorithm. The backpropagation algorithm uses gradient descent to update the weights. The update formula of the gradient descent method is as follows:

$$
\begin{gathered}
E_{\text {new }}^{l}=E_{\text {old }}^{l}-\mu \frac{\partial R}{\partial E_{\text {old }}^{l}}, \\
c_{\text {new }}^{l}=c_{\text {old }}^{l}-\mu \frac{\partial R}{\partial c_{\text {old }}^{l} .}
\end{gathered}
$$

The learning rate of gradient descent is used to represent $\mu$. It is a dynamic value in the education process, which is very large in the initial stage of education and gradually becomes smaller as the number of repetitions increases $[16,17]$. It can be seen from formulas (4) and (5) that the weight update classification method mainly uses parameter loss function classification. Therefore, the purpose of the weight information is to update each layer with such a gradient $[18,19]$.

In order to derive the sample error cost function and the deviation function of the parameters, the sensitivity is defined as the error change rate at the output:

$$
\varepsilon=\frac{\partial R}{\partial i}
$$

where $i$ is obtained by formula (5). For the offset $c$ in the parameter, it can be seen from equation (6) that, by the chain derivation rule $(\partial i / \partial c)=1$, we can get

$$
\frac{\partial R}{\partial c^{l}}=\frac{\partial R}{\partial i^{l}} \cdot \frac{\partial i^{l}}{\partial c^{l}}=\frac{\partial R}{\partial i^{l}}=\varepsilon^{l} .
$$

The sensitivity of different layers is different; it can be calculated as

$$
\varepsilon^{l}=\frac{\partial R}{\partial c^{l}}=\frac{\partial(1 / 2)\left(b^{L}-y_{p}\right)^{2}}{\partial c^{l}}=g^{\prime}\left(i^{l}\right) \cdot\left(b^{L}-y_{p}\right) .
$$

Because $b$ is also a function of $c$, $b=g\left(i^{l}\right)=g\left(E^{l} b^{l-1}+b^{l}\right)$, it needs to be multiplied. Here, all elements will increase exponentially $[6,20]$. Because all neural links have sensitivity, the sensitivity of each layer is a matrix.

In addition, the partial derivative function of the error cost function $R$ is obtained through the parameter weight $E$ :

$$
\frac{\partial R}{\partial E^{l}}=\frac{\partial R}{\partial i^{l}} \cdot \frac{\varepsilon i^{l}}{\varepsilon E^{l}}=\varepsilon^{l} b^{l-1} .
$$

At this time, each layer has achieved the classification required to update the weight using the descending gradient, namely, formulas (7) and (8). It can be seen that all gradients are related to sensitivity $[11,21]$. The sensitivity can be calculated by formula (9). In equation (9), $b^{l-1}$ is unknown, but we can establish the connection between layers through sensitivity [22]:

$$
\begin{aligned}
\varepsilon^{l} & =\frac{\partial R}{\partial u^{l}}=\frac{\partial R}{\partial u^{l+1}} \cdot \frac{\partial u^{l+1}}{\partial u^{l}}=\varepsilon^{l+1} \frac{\zeta\left(E^{l+1} b^{l}+c^{l+1}\right)}{\zeta i^{l}} \\
& =\zeta^{l+1} E^{l+1} \cdot g^{\prime}\left(i^{l}\right) .
\end{aligned}
$$

So backpropagation actually returns error information through layers of sensitivity. Equation (10) is the core formula of backpropagation. In the convolutional neural network, we expand the convolution kernel $k$ into the weight $E$ and then apply the above formula to solve the parameters in the convolutional neural network $[6,23]$.

2.1.3. Kalman Filter. The essence of the Kalman filter is to use the most advanced signal-to-noise ratio space model, using the estimated value of the last moment and the observed value of the current moment as the best evaluation benchmark and the minimum mean square error benchmark. Update the evaluation of the variable status and location based on the current estimate. The algorithm estimates the observation based on the established state transition equation and the minimum mean square error of the processed signal.

The hypothesis $e_{k} \sim M\left(0, W_{k}\right)$ is an independent process and $b_{k} \sim M\left(0, T_{k}\right)$ is also an independent process, independent of each other. And both are independent of the initial situation $x_{0} \sim M\left(\bar{x}_{0}, P_{0}\right)$. The loss function has the following basic Kalman filter types.

The initial conditions are

$$
\begin{aligned}
\widehat{x}_{0 \mid 0} & =\bar{x}_{0} ; \\
\tilde{x}_{0 \mid 0} & =x_{0}-\widehat{x}_{0 \mid 0} ; \\
\operatorname{cov}\left(\tilde{x}_{0 \mid 0}\right) & =P_{0} .
\end{aligned}
$$

The covariance matrices of the one-step advance prediction value and the prediction error are

$$
\begin{aligned}
& \hat{x}_{k \mid k-1}=G_{k-1} \hat{x}_{k-1 \mid k-1}, \\
& P_{k \mid k-1}=\operatorname{cov}\left(\hat{x}_{k \mid k-1}\right)=G_{k-1} P_{k-1 \mid k-1} G_{k-1}^{T}+W_{k-1} .
\end{aligned}
$$




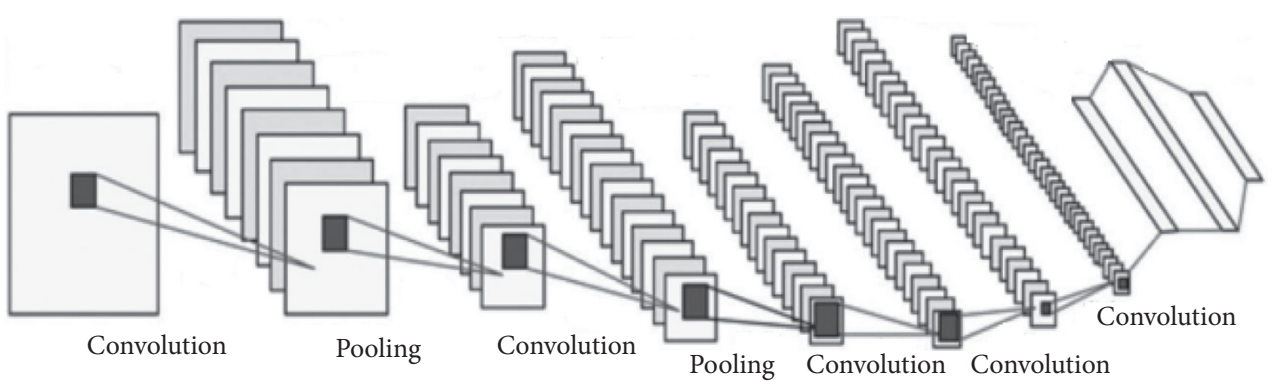

FIGURE 1: A simple convolutional neural network.

After obtaining the new measurement value, the filter update value and the corresponding filter error covariance matrix are, respectively,

$$
\begin{aligned}
& \hat{x}_{k \mid k}=\widehat{x}_{k \mid k-1}+L_{k}\left(s_{k}-J_{k} \widehat{x}_{k \mid k-1}\right) \\
& P_{k \mid k}=\operatorname{cov}\left(\hat{x}_{k \mid k}\right)=P_{k \mid k-1} J_{k}^{T}\left(J_{k} P_{k \mid k-1} J_{k}^{T}+T_{k}\right)^{-1} J_{k} P_{k \mid k-1} .
\end{aligned}
$$

Among them, $\tilde{x}_{k \mid k}=x_{k}-\widehat{x}_{k \mid k}$ is the filter residual, and the Kalman gain at this moment is

$$
L_{k}=P_{k \mid k-1} J^{T}\left(J_{k} P_{k \mid k-1} J_{k}^{T}+T_{k}\right)^{-1} .
$$

Formulas (12)-(16) are the five core formulas of Kalman filtering.

2.2. Physical Education. With the development of social economy and education, the competition between countries is actually based on the potential strategy of strengthening the country with talents. The requirements for talents not only require profound professional knowledge, to cope with the ever-changing and cruel social competition. And the school education that cultivates talents occupies a pivotal position. Therefore, in the traditional physical education teaching strategy, only focus on the transmission of knowledge and neglect the ability of students to learn knowledge independently, so that students form a dependent learning style. Without the guidance of teachers, students do not know how to allocate study time and arrange learning content, thereby affecting learning efficiency. In advocating quality education and lifelong education today, traditional teaching strategies are obviously not suitable for the needs of the development of the times [24].

The new era needs more talent who can independently acquire knowledge and carry out lifelong learning. To improve students' autonomous learning ability, it is necessary to guide students to learn how to learn. Changing teachers' teaching strategies under the background of new curriculum standards has received more and more attention. School education is an education with moral, intellectual, physical, aesthetic, and labor content. As one of the main contents of school education, that is, physical education, although it is different in form from other types of courses, it is consistent in teaching strategies [25]. They all adopt indoctrinating teaching methods while ignoring the students themselves.
This is not only not conducive to the cultivation of interest in sports, but also when students leave the school education environment, the physical exercise habits that have been formed will be interrupted and cannot form a lasting interest, which will affect the formation of the lifelong sports fitness concept of students. Therefore, changing the teaching strategy of physical education can also be regarded as an important factor to promote the reform of physical education in China. It has an irreplaceable important role in today's physical education. The old teaching methods have been difficult to adapt to the teaching of new knowledge in modern schools. In order not to be eliminated by the fiercely competitive society, teachers should establish a learningoriented concept of talent development. This must establish a new physical education strategy.

2.3. Teaching Strategies. The theoretical basis of educational strategy is educational theory. The final result of the education strategy is to achieve educational goals and improve educational effects. The design and formulation of education strategies must always pay attention to the two main goals of "purpose" and "optimization." Only by carefully analyzing the educational goals at all levels can teachers formulate educational strategies suitable for various educational goals and rationally use basic educational theories. In the process of designing educational strategies, teachers are always based on a single educational concept, and the guiding ideology of education is a set of single educational concepts: more specifically, for example, which education or teaching method should be selected, appropriate tools should be selected as educational support, the type of educational organization, how the education in the classroom should be managed in detail, and what methods and methods should be used for education: information feedback, the implementation of the formal evaluation and general evaluation of specific applications, the organization of overall educational activities, etc. The implementation of the guidance process and the theory of evaluation techniques are closely related, and the educational strategy cannot be completely separated from the educational theory.

Education is also learning. Therefore, the second theoretical basis is learning theory. The research content of educational strategy comes from the field of educational psychology, and the main source of its concept is learning strategy. In fact, this phenomenon is meaningful. This is the first time to discover the law of learning and then slowly 
develop a learning strategy in the process of transitioning from a learning strategy to an education strategy, which is suitable for educational practice. This theoretical structure is based on learning theory as the basis of strategic education theory and practice research. Nowadays, cognitive psychology has carried out many related researches in the fields of learning concepts, rules, and problem-solving, which have played an important guiding role in education. Developed psychology has conducted active and fruitful research on the laws of students' psychological development and the characteristics of thinking development. Among them, the research results of advanced psychology provide a theoretical basis for studying students' learning abilities and developing educational strategies. Moreover, action psychology and cognitive learning provide a theoretical basis and support for the formulation of educational strategies and learning strategies. In short, educational strategies based on learning theory have created space for their own survival and development. Particularly, the sports guidance strategy is necessary to absorb and learn from the learning strategies of other courses, to truly feel the difference between sports and the guidance of others, and to complement each other.

The third theoretical basis of educational strategy is educational theory. Different departments have their own characteristics, which are determined by the different nature and structure of science departments. Therefore, in the general education theory, the theory of the theme must be followed, reflect the characteristics of the theme, and have a center that fits the theme. From the perspective of physical therapy, its characteristics are mainly as follows: (1) there are specific characteristics of motor skills between concepts and concepts, forming a complex knowledge network; (2) extend the application program; (3) optimize sports language; (4) the structure of sports knowledge is based on a strict system of physical motor skills; and (5) the concept of exercise is usually an explanation of a specific mental state or athletic ability. According to the limitations of these characteristics, the physical law is also prescribed with specific specificity. For example, the performance of motor skills and the appropriateness of motor skills are the theoretical basis for learning sports, and education strategies must be based on this.

To sum up, explain the theoretical basis of education strategy from three aspects. Education strategy must be based on education theory, learning theory, and education theory. On the other hand, theoretical research on educational strategy can reflect the research value and role of educational strategy theory and establish the relationship between educational theory, learning theory, and educational strategy. On the other hand, educational strategies directly affect educational practice, combined with educational strategy theory and practice. It reflects the important value of teaching strategies.

2.4. WeChat Mobile Teaching Platform. Mobile learning refers to a new form of learning that uses wireless mobile communication network technologies such as mobile phones, $\mathrm{PAD}$, and wireless mobile communication equipment to obtain educational information, educational resources, and educational services [26]. Microlearning is a new perspective of M-learning and an important development direction of mobile learning. It was first proposed in 2004. Austrian scholar Lindner believes that microlearning is a new learning method based on microcontent and micromedia under the new media ecosystem. European scholar Bruck pays more attention to the new knowledge organization structure behind this concept, mini, loose but implicitly continuous knowledge units.

The mobile microlearning platform currently has no clear definition of the concept in the academic world. Through the reading of relevant literature and the attention of relevant public accounts, the author believes that the mobile microlearning platform is based on wireless networks and mobile terminals to build a platform suitable for fragmented learning. With the development of the times, more and more people use mobile devices instead of people to obtain information. Mobile microlearning platforms have the advantages of both mobile learning and microlearning, which are easy, on-demand, and efficient for learners in a dynamic state. The author believes that the characteristics of the mobile microlearning platform mainly include the following aspects:

(1) Mobility. Mobility means that learners can use portable wireless mobile terminal equipment to enter the learning state anytime and anywhere, to obtain relevant learning resources, to meet the needs of learners to learn, and to improve learning efficiency.

(2) Miniature. Miniature is mainly that learners focus on a short period of time and use micromobile devices to learn microknowledge blocks suitable for fragmented reading to improve the learner's current knowledge system structure.

(3) Personalization. Personalization means that learners can choose learning resources that suit them according to their own situation. Because learners have different learning foundations and learning interests, their learning needs are also very different. Learners can use the mobile microlearning platform. Create your own learning ecosystem independently and get a unique learning experience.

The selected mobile platform function is an important guarantee for whether learners can successfully complete mobile microlearning. The powerful functions of WeChat can provide a good environment for the development of mobile microlearning platforms and at the same time enable the platform to have both the strong interactivity and social interaction of WeChat.

\section{Research Experiment of Physical Education Teaching Strategy Based on Deep Neural Network Physical Test Analysis}

The experiment designed in this section is a research experiment of physical education teaching strategies based on 
deep neural network physical measurement analysis. Using literature data and experimental analysis methods, the experimental group and the control group are designed to compare before and after, and the students' cardiopulmonary function, muscle strength, and movement speed are analyzed. And other physical test indicators reflect the effectiveness of this paper's physical education teaching strategy research experiment.

\subsection{Research Methods}

3.1.1. Document Method. By documentary data method, this paper retrieved research papers related to this paper in the field of physical storage teaching methods through the China Journal Network, China Knowledge Network, and China Doctor and Master Papers Network since the year and conducted fraudulent and detailed reading of the articles in order to understand the physical storage. According to the latest research results and research status of this teaching method, understand its application in related fields. In addition, some related researches were consulted on the Internet. Provide the basis for the topic selection and research design of this research.

3.1.2. Experimental Analysis Method. The purpose of the experiment is to use deep neural network as an auxiliary teaching factor, through the comparative analysis of the experimental group and the control group in the research of physical education teaching strategy, to explore whether there are advantages in the research of physical education teaching strategy based on the deep neural network physical test analysis.

Experiment period is from March 2020 to July 2020, a total of 1 academic year.

Experimental subjects: in the second grade, two classes with new physical education strategies were randomly selected as experimental classes (128 people in total, including 63 boys and 65 girls). In addition, two classes that still use traditional physical education teaching methods are randomly selected as the control class (125 students in total, 61 males and 64 females).

3.2. Experimental Content and Methods. First, in the experimental period, the implementation factor of the experimental class is the PE teaching strategy based on deep neural network that is tried to be used in some classes. Second, in the experimental period, the control class still organizes teaching according to the traditional teaching plan and teaching method. Third, the whole experiment adopts a single-group comparative experiment method and collects data using methods such as before and after the experiment, questionnaire survey, observation, and discussion.

3.3. Selection of Experimental Effect Indicators. Physical performance indicators: according to the test content of the "Physique and Health Standards for Middle School Students," a number of indicators that reflect cardiopulmonary function, muscle strength, movement speed, and flexibility are selected as physical indicators that reflect the experimental effects.

Questionnaire survey indicators are students' interest in physical education and physical education through expert surveys, screening, and determination.

3.4. Data Statistics and Processing Methods. The test data of the experimental effect index and the data of the questionnaire survey are compared and analyzed before and after the experiment. If necessary, the test results of the experimental class can be compared and analyzed with the test results of the same indicators of the second-year students of the previous year. Circumstantial evidence of whether the physical education strategy based on the deep neural network has advantages. All data are processed on the computer using "SPSS" statistical software.

\section{Sports Teaching Strategy Based on Deep Neural Network Physical Test Analysis}

4.1. Survey of Results of Physical Education Teaching Scale. Through the measurement of five factors, it can be seen from Figure 2 that the cumulative contribution rate of the five factors is 59.471, which shows that the measurement results meet the requirements of the scale and have good structural validity.

Figure 3 shows the content of students' autonomous learning achievements in physical education classes: learning achievement awareness means that students summarize their learning situation after learning, consciously summarize various learning situations in subjective learning activities, and actively think. The questionnaire survey results show that if you remember the implementation of the course after class, only $9.6 \%$ and $22.6 \%$ are completely consistent and relatively consistent, and $30.4 \%$ and $27.8 \%$ are basically the same, not completely consistent. After class, only $6.1 \%$ of the learning objectives and $19.1 \%$ of the learning objectives can be well summarized. From these two aspects, students' awareness of sports other than sports is very low, and most students basically do not classify what they have learned in physical education. The reason for this phenomenon may be that other courses require a lot of study time, and the characteristics of physical education courses are necessary physical education courses. In order to unify the content learned in the classroom, practice is necessary, which is different from other courses. In addition, the four areas in which students can actually review their own shortcomings are relatively high level, in a dominant position in sports, academic performance, and self-criticism. This shows that if teachers can guide the entire teaching from these four aspects, the learning effect of students can be better improved. In order for students to achieve good learning results, teachers must actively use educational strategies to guide students' physical learning and autonomous learning results.

Figure 4 shows that most students have been able to realize the importance of physical education for their own 


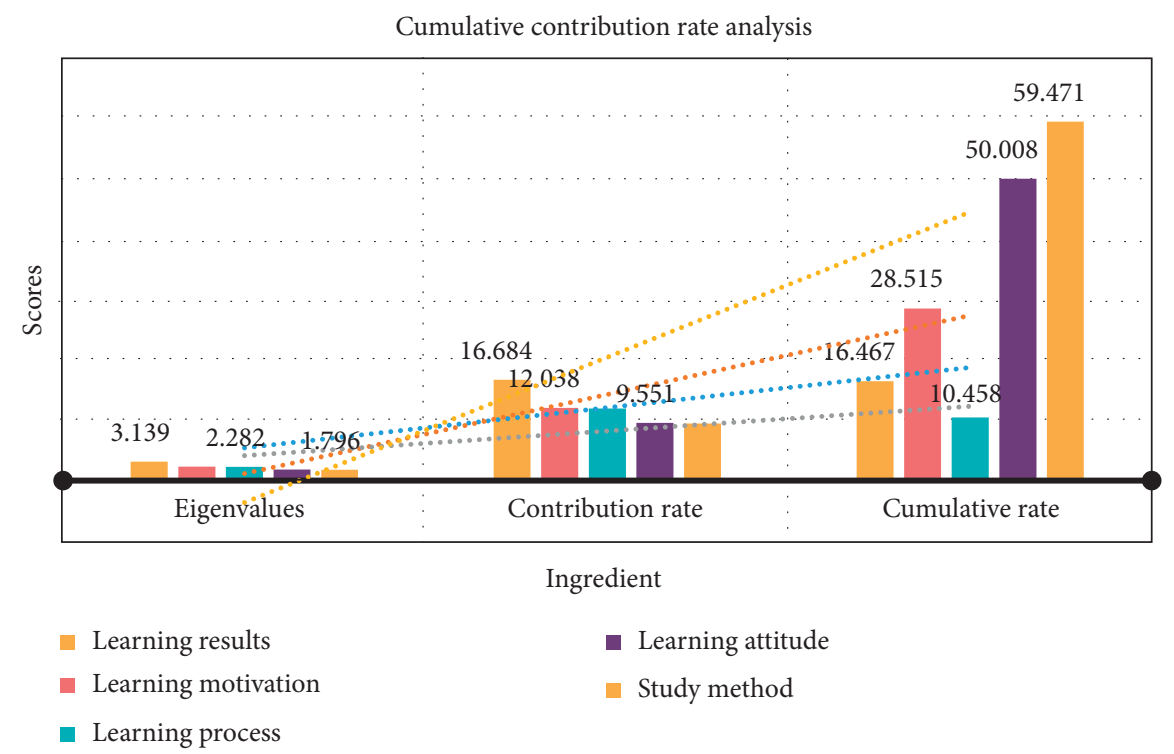

Figure 2: Cumulative contribution rate analysis.

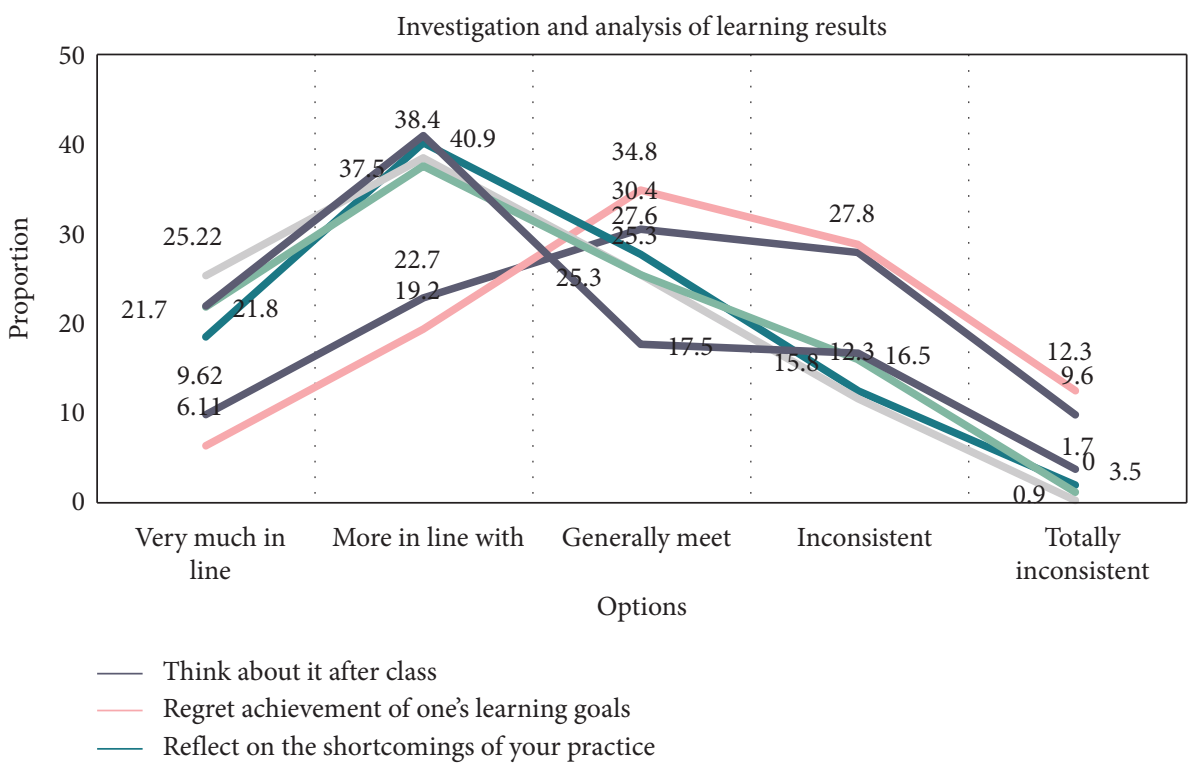

FIgURE 3: Investigation and analysis of learning results.

development, and their interest in physical education has gradually expanded. I was very happy when I thought that I was about to take physical education classes. The students who chose very suitable students reached 60\%. Therefore, when I took physical education classes, I felt relaxed and happy. I like to perform various exercises under the guidance of the teacher. The proportions that are more consistent reached $48.1 \%$ and $27.8 \%$, respectively. I feel that mastering a certain sports technique through diligent study and practice is a kind of fun. And the proportions of very consistent and relatively consistent reached $27.8 \%$ and $29.6 \%$, respectively. Encourage yourself to work harder; more than half of them are very consistent and relatively consistent. This shows that students' self-awareness for autonomous learning in physical education is at a relatively high level and reflects that students have a relatively high degree of preference for physical education. Teachers should seize the performance of students and set up various teaching situations to guide students to form the concept of autonomous learning in physical education.

It can be seen from Figure 5 that, in the process of physical education, pay attention to whether the essentials of the movement are mastered. The proportions of very consistent and relatively consistent reached $41.7 \%$ and $33.9 \%$, respectively. In the physical education class, I hope the teacher can provide several different practice methods, and he can choose one of them. The proportions of very consistent and relatively consistent reached $50.4 \%$ and $31.3 \%$, respectively, which shows that students have a relatively high level of understanding of the meaning of physical education. 


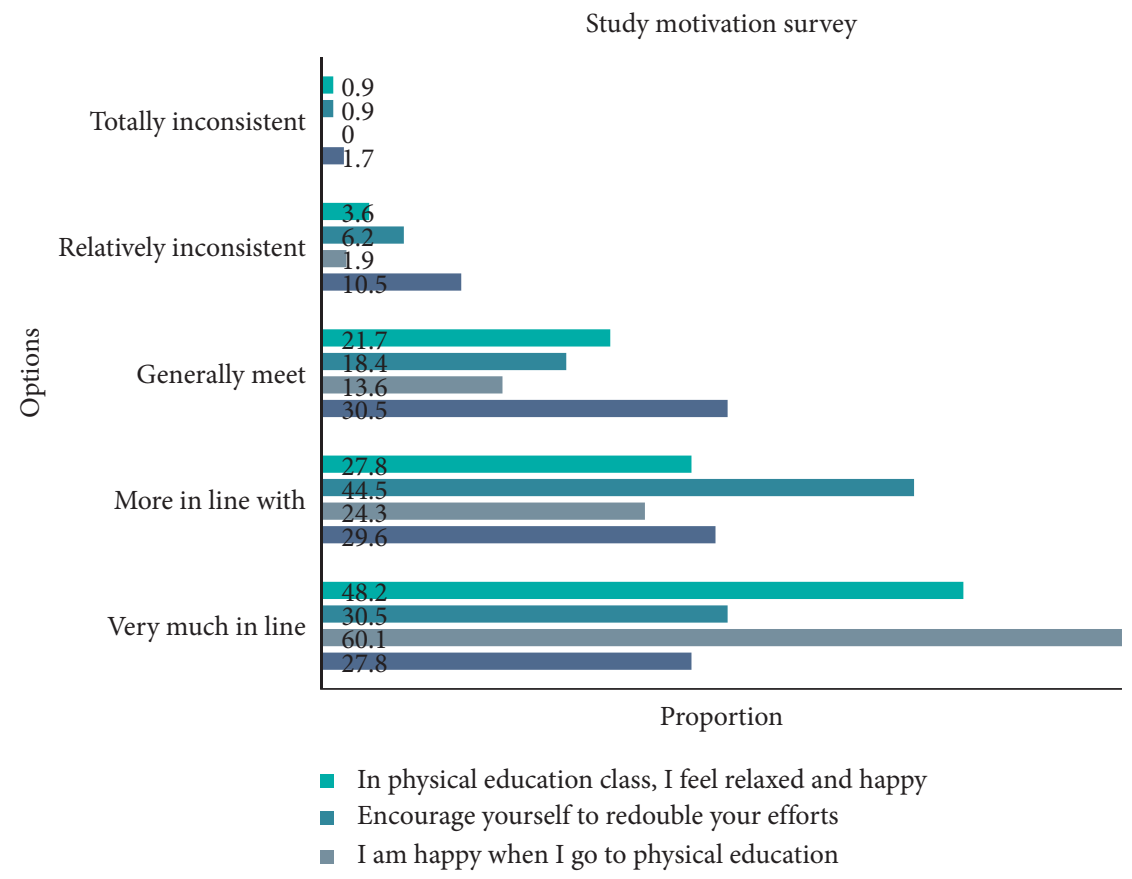

FIGURE 4: Study motivation survey.

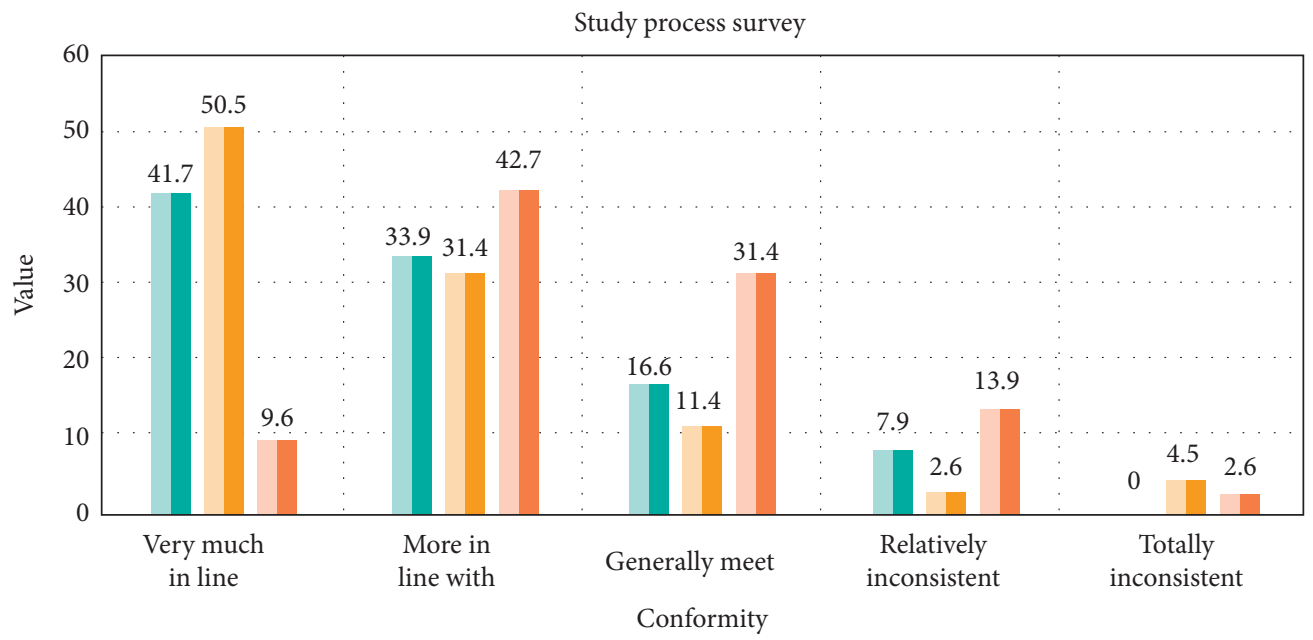

II Pay attention to the essentials of the movement
II I still insist on doing well
II Provide several different practice methods

Figure 5: Study process survey.

When encountering a project that I am not good at, I still insist on doing a good job carefully. The ratio of very consistent and relatively consistent is also about $1 / 2$. The analysis shows that students are in a good learning state during the learning process, but how to keep students maintaining such a good learning state is also an aspect that physical education teachers should pay attention to. Nearly $1 / 2$ of the students' learning status is still low. This shows that students do not have a comprehensive and systematic understanding of the basic standards that they need to achieve in autonomous sports learning.
It can be seen from Figure 6 that when attending physical education class, students pay attention to the basic requirements of the learning goals proposed by the teacher. And the proportions of very consistent and relatively consistent reached $32.2 \%$ and $41.7 \%$, respectively. The students' attention is very concentrated on physical education. And the proportions of very consistent and relatively consistent reached $34.8 \%$ and $51.3 \%$, respectively. From these two points, it shows that the students' learning attitude is very positive, but they only pay attention to the cooperation with the teacher. However, in the physical education 


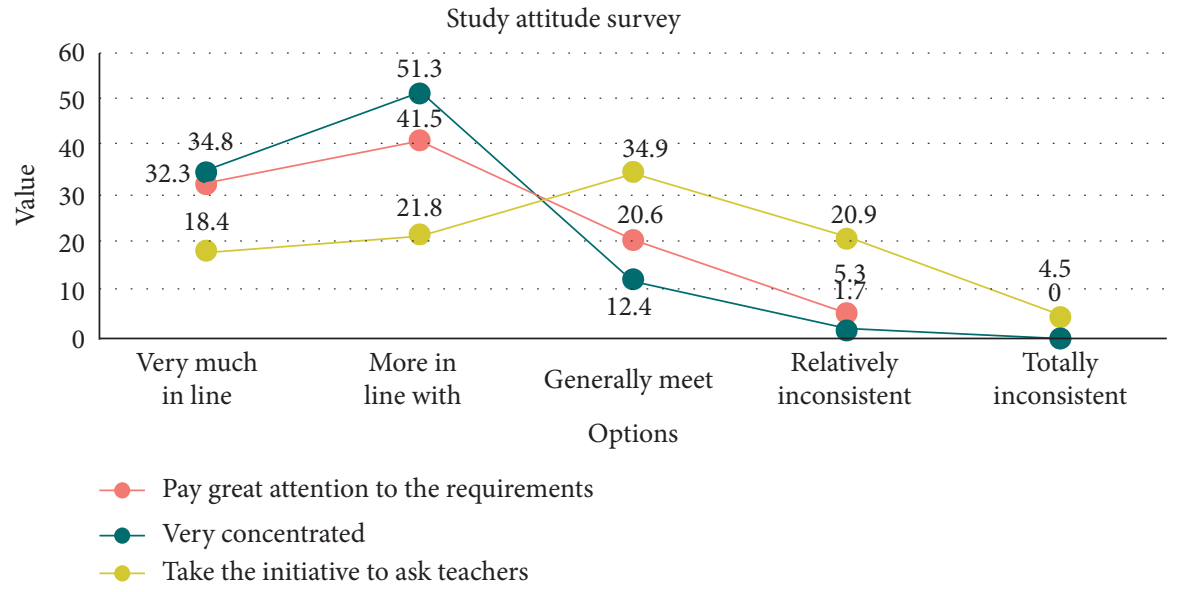

Figure 6: Study attitude survey.

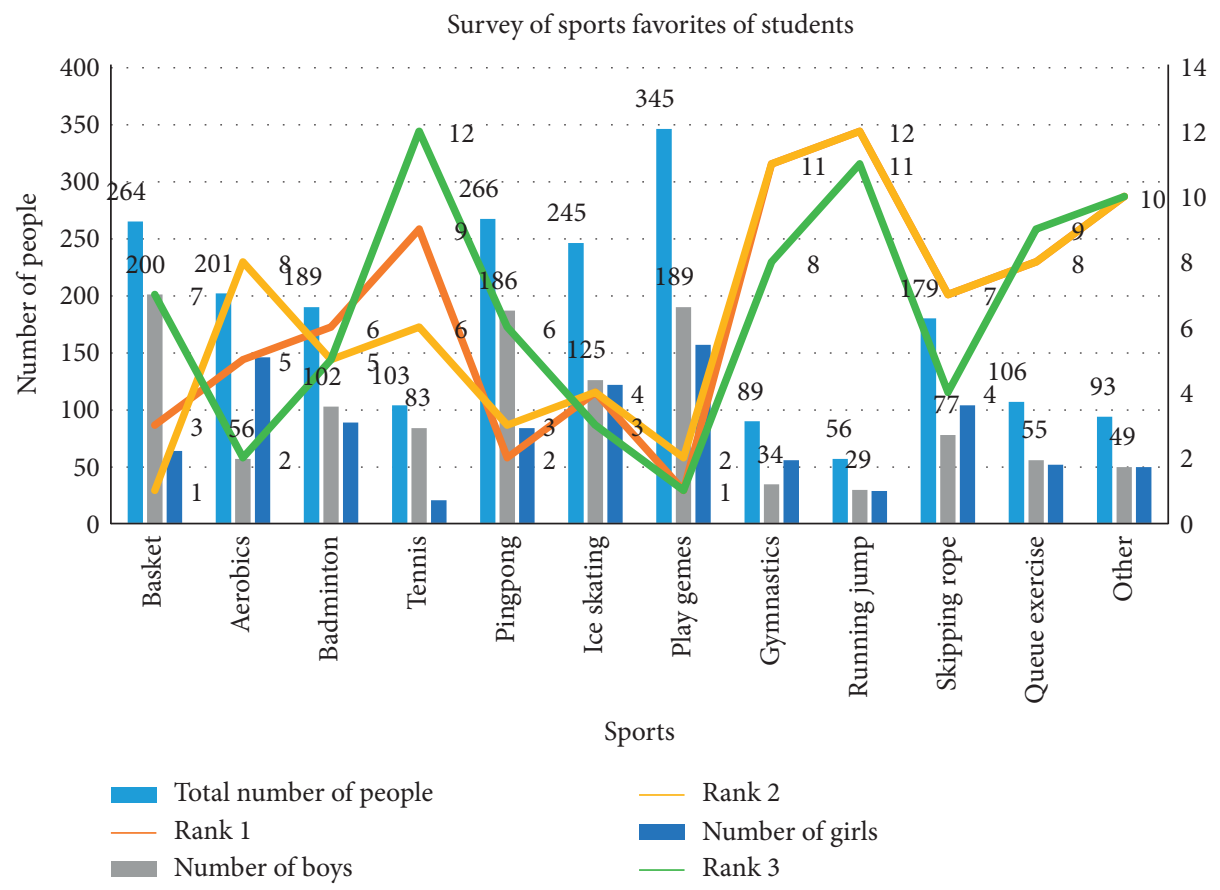

Figure 7: Survey of sports favorites of students.

class, when encountering uncomprehending places, they will take the initiative to ask teachers or classmates. The proportion of very consistent and relatively consistent is relatively low. This shows that the interaction between students is still relatively small. These three problems also show that the students' learning attitude is at a relatively high level, and the level of self-monitoring is also high, but the student's performance is not very satisfactory. How to make better use of the initiative of students in sports learning requires teachers to use relevant strategies to guide students' learning independently and guide students to learn from each other, which poses a new challenge to teachers' teaching.

Figure 7 shows the survey data of students' favorite sports. Generally speaking, the types of physical education classes ranked in the front are game classes, table tennis classes, basketball volleyball classes, skating, and so on, while running, jumping, throwing, and gymnastics classes are not popular with students. Boys' favorite sports are basketball, volleyball, football lessons, game lessons, table tennis lessons, skating, and so on. Girls' favorite sports lessons are games, aerobics, skating, skipping rope, and shuttlecock. It can be seen from the types of physical education classes that students like that game classes are the most popular, which are consistent with the age characteristics of the students, followed by ball events, due to the lack of sports venues and equipment; although students have little contact with sports in physical education, the emerging skating event is one of the sports that students like. Boys prefer more competitive sports, such as basketball, foot, and volleyball classes, while girls prefer sports with a relatively small amount of exercise, 
TABLE 1: Comparison of the results of boys in the experimental class and the control class.

\begin{tabular}{lccccc}
\hline Class & Gender & Number of people & Back toss a solid ball & Standing long jump & Curve run \\
\hline Experimental class & Male & 63 & 10.48 & 2.12 & 7.78 \\
Control class & Male & 61 & - & 12.49 & 2.22 \\
$t$ & - & - & 2.34 & 1.65 & 7.56 \\
Sig & - & - & 0.028 & 0.116 & 0.14 \\
$P$ & - & $P<0.05$ & $P>0.05$ & $P>0.05$ \\
\hline
\end{tabular}

TABLE 2: Comparison of girls' scores in the experimental class and the control class.

\begin{tabular}{lccccc}
\hline Class & Gender & Number of people & Back toss a solid ball & Standing long jump & Curve run \\
\hline Experimental class & Female & 65 & 5.58 & 1.53 & 9.44 \\
Control class & Female & 64 & 5.77 & 1.54 & 0.445 \\
$t$ & - & - & 0.635 & 0.667 & 0.441 \\
Sig & - & - & 0.546 & $P>0.05$ & 0.664 \\
$P$ & - & - & $P>0.05$ & $P>0.05$ \\
\hline
\end{tabular}

TABLE 3: Comparison of male scores between the experimental group and the control group.

\begin{tabular}{lccccc}
\hline Class & Gender & Number of people & Back toss a solid ball & Standing long jump & Curve run \\
\hline Experimental class & Male & 63 & 11.72 & 2.24 & 7.36 \\
Control class & Male & 61 & 11.63 & 2.24 & 7.58 \\
$t$ & - & - & 0.198 & 0.065 & 1.009 \\
Sig & - & - & 0.844 & 0.959 & 0.335 \\
$P$ & - & - & $P>0.05$ & $P>0.05$ & $P>0.05$ \\
\hline
\end{tabular}

TABLE 4: Comparison of girls' scores in the experimental group and the control group.

\begin{tabular}{lccccc}
\hline Class & Gender & Number of people & Back toss a solid ball & Standing long jump & Curve run \\
\hline Experimental class & Female & 65 & 6.56 & 1.61 & 9.13 \\
Control class & Female & 64 & - & 5.82 & 1.58 \\
$t$ & - & - & 3.734 & 1.238 & 9.46 \\
Sig & - & - & 0.001 & 0.228 & 3.282 \\
$P$ & - & $P<0.01$ & $P>0.05$ & 0.002 \\
\hline
\end{tabular}

such as games and aerobics, which also reflect the physical and psychological differences between boys and girls.

4.2. Results and Analysis of Student Physique Test. The data analysis in Table 1 shows that there is a significant difference between the boys in the experimental class and the control class in the comparison of the results of the solid ball after throwing. This is because the boys in the control class are better than the students in the experimental class in throwing items. But in standing long jump and corner running, the $P$ values of boys' physical fitness in the two classes are both greater than 0.05 , and there is no significant difference in these two physical fitness measurements. According to Table 2, the $P$ values of girls' physical fitness in these three items are also greater than 0.05 , indicating that there is no significant difference in these three items.

The data in Table 3 show that the $P$ values of the boys in the experimental class and the control class in the three physical fitness are all greater than 0.05 , which is limited to the relatively short time of the experiment. The data of the boys in the two classes on these three items show no significant difference. According to Table 4, the $t$-test was performed on the posttest results of the three items of girls, and the $P$ values were all less than 0.05 , and there were significant differences, especially in the comparison of the results of the postthrowing solid ball and the corner running. In the two tests, the $P$ values of the items are all less than 0.01 ; there is a very significant difference.

\section{Conclusion}

This paper mainly studies the construction of WeChat mobile teaching platform in the reform of PE teaching strategy based on deep neural network, breaks through the shackles of traditional physical education, introduces deep neural networks into physical education, conducts a more comprehensive and detailed analysis of students' physical test items, and summarizes and applies physical education strategies that are more suitable for students' growth and interest in sports. In the WeChat mobile teaching platform, the physical fitness of students has been effectively improved, and the goal of physical education has been achieved. The innovation of this paper lies in the use of a combination of theoretical analysis and empirical analysis. Under the in-depth study of deep neural network theory, 
combined with the analysis of students' physical test scores, the research on PE teaching strategies is carried out with reasonable evidence. The shortcomings of this paper are that the amount of student data collected is not enough, the experiment time is not long enough, and the experimental data need to be viewed and supplemented rationally. It is hoped that the research on the teaching strategy of physical education in this paper can promote the development of physical education and provide theoretical support for physical education.

\section{Data Availability}

No data were used to support this study.

\section{Conflicts of Interest}

The authors declare that they have no potential conflicts of interest.

\section{Acknowledgments}

This work was supported by the Philosophy and Social Sciences Programs of Henan Province (2020BTY008), National Key Research and Development Programs (2018YFC0807203), Scientific and Technological Projects of Henan Province (202102110105), and College Key Scientific Research Projects of Henan Province (20B340001).

\section{References}

[1] J. C. Peterson, J. T. Abbott, and T. L. Griffiths, "Evaluating (and improving) the correspondence between deep neural networks and human representations," Cognitive Science, vol. 42, no. 8, pp. 2648-2669, 2018.

[2] X. Xu, D. Cao, Y. Zhou, and J. Gao, "Application of neural network algorithm in fault diagnosis of mechanical intelligence," Mechanical Systems and Signal Processing, vol. 141, Article ID 106625, 2020.

[3] G. Escriva-Boulley, D. Tessier, N. Ntoumanis, and P. Sarrazin, "Need-supportive professional development in elementary school physical education: effects of a cluster-randomized control trial on teachers' motivating style and student physical activity," Sport, Exercise, and Performance Psychology, vol. 7, no. 2, pp. 218-234, 2018.

[4] J. V. Nielsen, H. Klakk, A. Bugge, M. L. Andreasen, and T. Skovgaard, "Implementation of triple the time spent on physical education in pre-school to 6th grade: a qualitative study from the programme managers' perspective," Evaluation and Program Planning, vol. 70, pp. 51-60, 2018.

[5] S. K. Biswas, D. Devi, and M. Chakraborty, "A hybrid case based reasoning model for classification in internet of things (iot) environment," Journal of Organizational and End User Computing, vol. 30, no. 4, pp. 104-122, 2018.

[6] A. Lucas, M. Iliadis, R. Molina, and A. K. Katsaggelos, "Using deep neural networks for inverse problems in imaging: beyond analytical methods," IEEE Signal Processing Magazine, vol. 35, no. 1, pp. 20-36, 2018.

[7] J. Qi, J. Du, S. M. Siniscalchi, and C.-H. Lee, "A theory on deep neural network based vector-to-vector regression with an illustration of its expressive power in speech enhancement,"
IEEE/ACM Transactions on Audio, Speech, and Language Processing, vol. 27, no. 12, pp. 1932-1943, 2019.

[8] J. Hui, M. Du, X. Ye, Q. Qin, and J. Sui, "Effective building extraction from high-resolution remote sensing images with multitask driven deep neural network," IEEE Geoscience and Remote Sensing Letters, vol. 16, no. 5, pp. 786-790, 2019.

[9] J. Jin, C. Zhang, F. Feng, W. Na, J. Ma, and Q.-J. Zhang, "Deep neural network technique for high-dimensional microwave modeling and applications to parameter extraction of microwave filters," IEEE Transactions on Microwave Theory and Techniques, vol. 67, no. 10, pp. 4140-4155, 2019.

[10] H. Xiong, X. Gao, S. Li et al., "Interpretable structured multimodal deep neural network," Moshi Shibie Yu Rengong Zhineng/Pattern Recognition and Artificial Intelligence, vol. 31, no. 1, pp. 1-11, 2018.

[11] C. Sánchez-Sánchez and D. Izzo, "Real-time optimal control via deep neural networks: study on landing problems," Journal of Guidance, Control, and Dynamics, vol. 41, no. 5, pp. 1122-1135, 2018.

[12] Y. Cheng, D. Wang, P. Zhou, and T. Zhang, "Model compression and acceleration for deep neural networks: the principles, progress, and challenges," IEEE Signal Processing Magazine, vol. 35, no. 1, pp. 126-136, 2018.

[13] C. Roure and D. Pasco, "Exploring situational interest sources in the French physical education context," European Physical Education Review, vol. 24, no. 1, pp. 3-20, 2018.

[14] Y. Xu, Y. Lao, W. Liu, Z. Zhang, X. You, and C. Zhang, "Mathematical modeling analysis of strong physical unclonable functions," IEEE Transactions on Computer-Aided Design of Integrated Circuits and Systems, vol. 39, no. 12, pp. 4426-4438, 2020.

[15] L. Huang, Y. Liang, F. Huang, and D. Wang, "A quantitative analysis model of grid cyber physical systems," Global Energy Interconnection, vol. 1, no. 5, pp. 618-626, 2018.

[16] Z. Zhang, M. Tang, and M. Lan, "Diagnostic analysis on physical quantities of spring hail weather in hunan," Meteorological and Environmental Research, vol. 9, no. 2, pp. 5-7, 2018.

[17] H. Guo, Y. Xu, H. Chen, X. Zhang, and W. Qin, "Corresponding-point methodology for physical energy storage system analysis and application to compressed air energy storage system," Energy, vol. 143, pp. 772-784, 2018.

[18] E. Tenison and R. Touger-Decker, "Impact of e-learning or blended learning versus face-to-face learning in regard to physical examination skills, knowledge, and attitudes among Health professions students," Topics in Clinical Nutrition, vol. 33, no. 3, pp. 259-270, 2018.

[19] S. Cohen and L. Debettencourt, "Teaching children to be independent learners: a step-by-step strategy," Focus on Exceptional Children, vol. 16, no. 3, pp. 1-12, 2018.

[20] P. Nascimento, D. Souza, P. Filho, R. Ribeiro, H. Mezzalira Teixeira, and A. Batista Lopes do Nascimento, "Do dentistry and physical education students know the importance of mouthguard usage in sports practice?" $R G O$, vol. 67 , no. 3 , pp. 1-7, 2019.

[21] M. Kahng, P. Y. Andrews, A. Kalro et al., "ActiVis: visual exploration of industry-scale deep neural network models," IEEE Transactions on Visualization \& Computer Graphics, vol. 24, no. 1, pp. 88-97, 2018.

[22] X. Xu, Y. Ding, S. X. Hu et al., "Scaling for edge inference of deep neural networks," Nature Electronics, vol. 1, no. 4, pp. 216-222, 2018

[23] E. Weinan and Q. Wang, "Exponential convergence of the deep neural network approximation for analytic functions," 
Science China Mathematics, vol. 61, no. 10, pp. 1733-1740, 2018.

[24] C.-H. Chen, F. Song, F.-J. Hwang, and L. Wu, "A probability density function generator based on neural networks," Physica A: Statistical Mechanics and Its Applications, vol. 541, 2020.

[25] S. Wan, L. Qi, X. Xu, C. Tong, and Z. Gu, “Deep learning models for real-time human activity recognition with smartphones," Mobile Networks and Applications, vol. 25, pp. 743-755, 2019.

[26] S. Tu, X. Yan, K. Jie, M. Ying, and C. Huang, "WeChat: an applicable and flexible social app software for mobile teaching," Biochemistry and Molecular Biology Education, vol. 46, no. 5, pp. 555-560, 2018. 